\title{
Uma memória das africanidades
}

\author{
Denise Camargo \\ E-mail:deca@pbrasil.com.br
}

Fotógrafa, fotojornalista, doutora em Artes e docente do Centro Universitário Senac (São Paulo-SP)

e da Universidade do Vale do Itajaí (Balneário Camboriú-SC)

$\mathrm{N}$

o embarque forçado para a travessia transatlântica, os negros africanos cap turados pela escravidão marcavam a separação de suas origens por meio de um ritual. Homens deveriam dar nove voltas e mulheres, sete (Barbieri, 1998) em torno de um frondoso, imponente, acolhedor e centenário baobá que ficaria conhecido como a "árvore do esquecimento".

Essa atitude, executada entre outros motivos para apagar memórias, parecia não combinar com os valores da cultura africana de reforçar e respeitar raízes, saberes e identidades. Entretanto, seu simbolismo

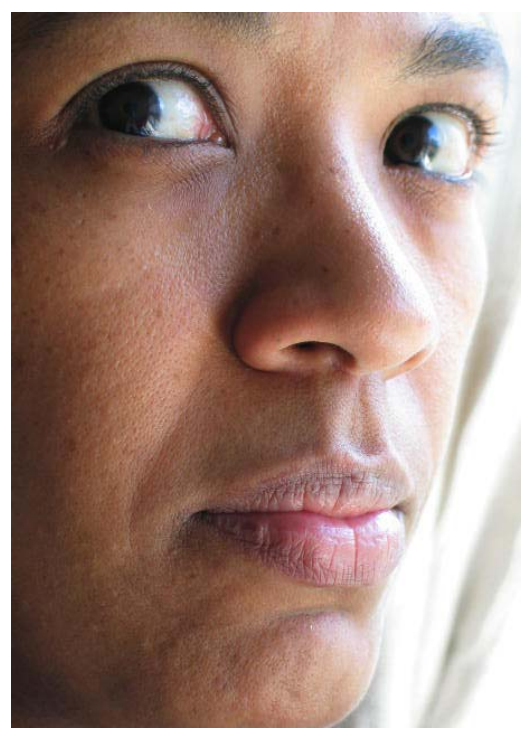
memória e identidade étnicas que, não raro, sobrevivem nas produções culturais (de) e sobre afro-descendentes. Tradições, hábitos, visões de mundo têm sido evidenciados no registro, difusão e fruição, por exemplo, das imagens fotográficas, compondo um inventário das manifestações de uma cultura viva e capaz de transmitir e interpretar a memória sobre ela.

Fotógrafos que dedicam seu trabalho ao que poderíamos chamar de "temática negra” parecem reverter esse movimento ancestral e, nesse retorno, as "imagens fotográficas constituem um dos meios ajudou a conceituar a história das culturas de origem negro-africana no Brasil como, notadamente, marcada pela preservação de uma mais criativos e eficazes para a identificação, o reconhecimento e a representação das singularidades nacionais de uma cultura, tanto quanto 
uma das formas de expressão da sua própria existência” (Turazzi, 1998: 09).

As manifestações culturais e religiosas da cultura de matriz negra têm sido objeto de minha fotografia e, nesse percurso de imagens e pesquisas, tenho notado a busca por formas visuais de pertencimento, das quais também compartilho, na produção de fotógrafos como Adenor Gondim, Anízio de Carvalho, André Vilaron, Aristides Alves, Bauer Sá, Eustáquio Neves, Januário Garcia, Lita Cerqueira, Luiz Paulo Lima, Márcio Vasconcellos, Ricardo Teles, Roberto Esteves, Vantoen Pereira Junior, Wagner
Celestino, Walter Firmo, entre outros fotógrafos brasileiros, e suas diferentes abordagens técnicas, estéticas e teóricas do tema.

Da cultura que foi desenraizada nas violências provocadas pela escravidão e devastação dos elos africanos, eles elaboram não só documentos, mas obras que criam e preservam uma memória das africanidades. É nesse contexto que converso com Adenor Gondim, André Vilaron, Bauer Sá, Eustáquio Neves, Luiz Paulo Lima e Januário Garcia, nesta espécie de "entrevista coletiva".

\title{
Revelando segredos e identidades
}

\begin{abstract}
Resgate - Adenor Gondim, que aspectos da cultura de origem afro-brasileira são retratados em seu trabalho?

Gondim - Minhas fotografias mostram o modo diferenciado no vestir das mulheres: saias, anáguas, panos-da-costa, panos de cabeça (ojás) e uma diversidade de adereços como anéis, pulseiras, colares. E também indumentárias usadas por orixás, eguns (antepassados) e caboclos nos rituais que, embora brasileiros,
\end{abstract}

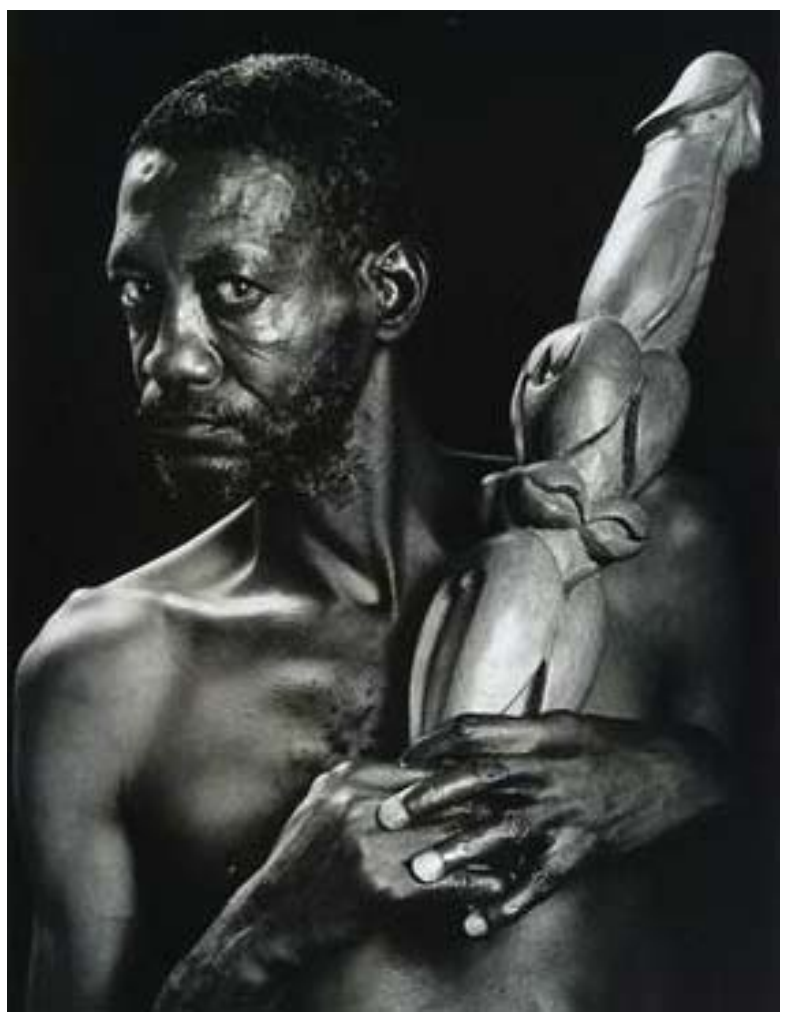

Exu, de Bauer Sá: poéticas visuais construtoras de memórias ancestrais são de origem africana. Trago a atividade religiosa dos ritos, das oferendas, e rezas, o xirê (festa pública que celebra os orixás), as comidas, a música e a dança. No ensaio Itaylê Ogun me dedico ao universo de dois personagens significativos da cultura afro-descendente da Bahia, Narcísea Cândida da Conceição, a Mãe Filhinha, irmã da Boa Morte de Cachoeira e iyalorixá do Ilê Itaylê Ogun; e José Adário dos Santos, o Zé Diabo, ferreiro dos orixás da Bahia, só 
para citar dois importantes exemplos.

Resgate - Eles preservam técnicas e saberes. São verdadeiros patrimônios para a cultura imaterial. Que outros trabalhos seus revelam a preocupação com uma imagem que preserva memórias das africanidades no Brasil?

Gondim - Acho que o ensaio publicado em Arte e Religiosidade no Brasil - Heranças Africanas, dedicado à Irmandade de Nossa Senhora da Boa Morte de Cachoeira, e também os trabalhos que tratam do sincretismo religioso na Bahia, como Nego Fugido, São Lázaro e São Roque "Obaluaiê e Omolu”, Iemanjá, Romaria do Bom Jesus da Lapa, Beato Pedro Batista - Santa Brígida.

Resgate - Eustáquio Neves, de que forma suas imagens propõem uma reconstrução artística, criativa, de um passado que é atualizado e revivido pelos rituais?

Neves - Acredito que além da informação pelos diversos meios, a herança ancestral e a imaginação são os principais mecanismos. Creio que a manutenção da herança cultural por meio das manifestações religiosas na comunidade dos Arturos, em Contagem
(MG), seria um exemplo. E também a comunidade do Baú, onde pude registrar vários aspectos da vida cotidiana, as celebrações da vida comum e as manifestações religiosas em todo seu ritual.

Resgate - André Vilaron, como você explora esse universo?

Vilaron - No Rio de Janeiro, onde me criei, convivemos com malandros e fortes referências a Exu nas esquinas, escamoteadas, como costumam estar. Faz parte do cotidiano da cidade uma certa malícia de corpo, um jeito Zé Pelintra de ser de alguns personagens da boemia, além de outros elementos, como a devoção a São Jorge. O mesmo São Jorge associado a Ogum, no Rio, em Salvador, é Oxóssi. E foi lá mesmo, na Bahia, que se estabeleceu o segredo desse orixá caçador, deixando a África pelas mentes e corpos de seus sacerdotes, escravizados, para se fixar aqui em rituais seculares, como no Ilê Iyá Omin Axé Iyá Massê, a tradicional Sociedade São Jorge do alto do Gantois. Faço imagens do universo simbólico dos rituais - ou que fazem referência a eles, nas tradições banto, jeje ou iorubá, candomblé, umbanda, tambor de mina, candombe, catimbó, no Rio de Janeiro, na Bahia, no Maranhão e em Minas Gerais.
Resgate - Bauer Sá, seus retratos em estúdio, verdadeiras poéticas visuais, são densos e carregados de aspectos míticos. Os retratados olham fixamente nos seus olhos e tocam em memórias que são suas ou de seus personagens? Sá - Quando os vejo por meio de minhas pesquisas visuais registro um olhar de artista que se identifica com a cultura africana e coloca nela sua inspiração, criatividade e vivências. A educação e a cultura andam quase juntas, fazendo com isso a transformação das ausências em presenças de nossas memórias afro-descendentes.

Resgate - Januário Garcia, você acha que o termo cultura afro-brasileira reduz esse conceito. Você pode nos explicar isso?

Garcia - Sempre pautei o meu trabalho dentro da perspectiva da cultura brasileira de matrizes africanas. É com esse enfoque que vamos perceber que essas matrizes influenciaram, decisivamente, a maneira de ser, agir, pensar e estar de cada brasileiro.

Resgate - Qual a participação de sua fotografia na formulação desse conceito? Garcia - Como profissional, 
nesse mercado competitivo, sempre me considerei um fornecedor de imagens para as agências de publicidade, fotografando para anúncios, para as gravadoras, para capas de discos, um trabalho comercial. Paralelamente, no entanto, meu trabalho pessoal está voltado para a comunidade negra. Acredito que toda luta tem que ter um cronista. Desde 1976, venho fazendo crônicas do Movimento Negro, por meio da imagem. São três livros publicados sobre o assunto: História dos Remanescentes de Quilombo do Estado do Rio de Janeiro - $A$ Verdade que a História não Conta, em parceria com o ator Antônio Pitanga. Nesse livro traço um panorama fotográfico de todas as comunidades remanescentes de quilombo do Estado do Rio de Janeiro reconhecidas. Outra publicação é 1980/2005 - 25 Anos do Movimento Negro no Brasil, uma memória fotográfica com textos de vários militantes, e Diásporas Africanas na América do Sul - Uma Ponte Sobre o Atlântico, em pareceria com o antropólogo Julio César de Tavares. Nesse livro trazemos a história e a realidade, nas imagens das comunidades negras de todos os países que fazem fronteira com o Brasil, do Uruguai ao Suriname.

Resgate - Bauer Sá, nos rituais de tradição africana o segredo é um elemento que preserva a memória tradicional.

Sá - As imagens não abalam o segredo, elas simplesmente mostram a existência de um processo religioso, experiências que são mantidas por fé e sincretismo e ajudam a manter os próprios rituais.

Resgate - André Vilaron, quando dá a ver a imagem não romperia com o segredo e, portanto, com uma memória interna do ritual? Vilaron - Não vejo a fotografia - discutindo aqui somente o suporte - como um meio capaz de revelar o segredo. Ou, pelo menos, um meio "superior", que possa revelá-lo de uma forma que uma gravação de áudio, um desenho ou uma descrição escrita, em detalhes, não possam fazê-lo. A questão da imagem fotográfica ficaria então nos termos de que alguns momentos dos cultos e alguns rituais são fechados à participação de pessoas de fora ou não-autorizadas. E alguns o são, inclusive, não somente para resguardar o segredo, mas para a própria proteção das pessoas estranhas ao ritual.

Resgate - Januário Garcia, você que também é iniciado, que teve a oportunidade ir a Ilê Ifé, Reino de Oyó, na Nigéria (iorubá), onde são cultuados os orixás e também ao Togo (jeje), onde se cultuam os eguns ...

Garcia - Olha, são exatamente esses segredos que chegaram aqui trazidos por etnias diferentes, e, juntados, mixados, tornaram-se os elementos bási$\cos$ da cultura brasileira. $\mathrm{Na}$ tradição religiosa que se desenvolveu no Brasil, alguns cultos de origem banto e nagô foram perdidos, o que fez das religiões de matrizes africanas no Brasil as mais violadas na sua ortodoxia. O que temos aqui são religiões brasileiras de matrizes africanas.

Resgate - Adenor Gondim, de que forma a imagem fotográfica causou impactos nesse processo de preservação de uma memória que parece ter sido perdida?

Gondim - Somos afro-descendentes. Os cultos sofreram adaptações regionais no Pará, Maranhão, Pernambuco, Bahia, Rio de Janeiro, São 
Paulo, Rio Grande do Sul. A partir do momento em que uma fotografia passa a existir ela é passado, ela é memória de alguma coisa, pessoa, lugar. Quando olhamos fotos do final dos séculos XIX e XX do povo da Bahia e de África, vemos trajes, ritos e costumes distintos. Os afro-descendentes brasileiros recriaram a África no Brasil e preservam essas recriações. Influenciaram e influenciam, torrencialmente, o processo de civilização brasileiro e estão presentes em tudo e todos, na língua, na comida, no traje, na música e dança, nas religiões e nos costumes. É pela memória desse processo que andam os meus olhares.

Resgate - Luiz Paulo Lima, sua documentação fotográfica em locais como Namíbia, Benin, África do Sul, Botsuana propõe um retorno à cultura da África?

Lima - Entendo o meu trabalho como lembranças e vivências pessoais retratadas, simbolicamente, por meio da fotografia. Não tenho a preocupação com a memória ancestral e, sim, com a minha opinião e expressão. Uma cultura não se preserva, ela é vivida e compartilhada. Por isso adoto sempre esta palavra e seus significados no plural: culturas.

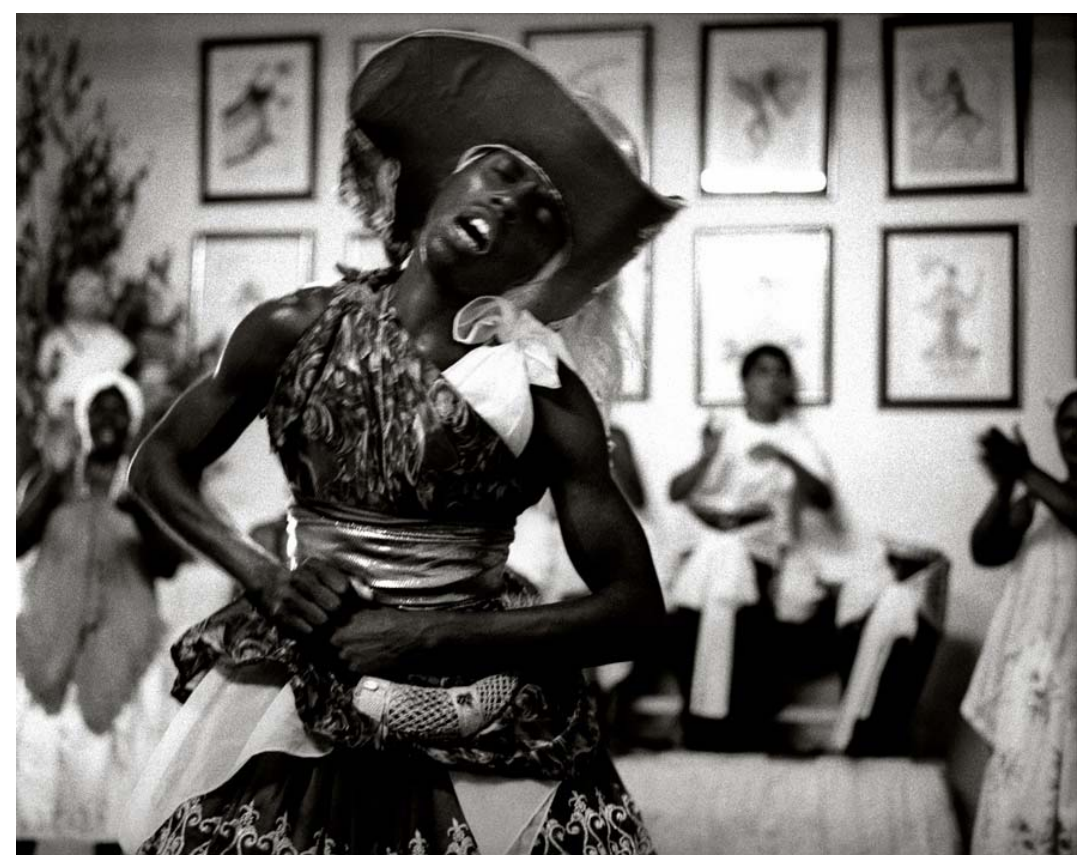

Oxóssi, de André Vilaron: referências ao universo simbólico dos rituais

Resgate - Eustáquio Neves, você cria e recria realidades, reiterando a adesão do fotógrafo às questões de memória e identidade do negro brasileiro. Há algum passado revelado nas suas imagens, uma memória ancestral?

Neves - Sim, há um inconsciente coletivo que nos remete a uma memória que vai além dessa vivida. Um exemplo é o modo como alguns comportamentos são reproduzidos e repetidos, mesmo que não tenham sido ensinados e aprendidos. Minha mãe cantava para mim no meu aniversário. As mães de dois amigos meus, um americano, um africano conservam esse mesmo hábito.
Resgate - Januário Garcia, e suas memórias? Elas pertencem a sua fotografia?

Garcia - Vejo esse meu trabalho como um etnodocumento e, ao mesmo tempo, um jato de luz afirmativo que valoriza aspectos, inegavelmente, positivos da contribuição de uma etnia na formação do nosso país. $\mathrm{Na}$ realidade, são momentos de negros vistos por um olhar negro. Nesse conjunto de imagens não existe um distanciamento do fotógrafo. É estabelecida uma cumplicidade entre quem fotografa e quem é fotografado. Ou seja: sou eu visto por um "não-diferente", 
e sou eu vendo um igual. Isso não estabelece segredo nenhum.

Resgate- Eustáquio Neves, que memória é essa, então? Como ela se manifesta na imagem fotográfica?

Neves - Uma imagem pode ter diversas leituras. Mas os signos são o principal meio que eu utilizo na construção dessa memória no meu trabalho.

Resgate - Januário Garcia, como a fotografia contribui nesse processo?

Garcia - Bem, a fotografia quando você acaba de fazer ela já é passado e é memória. Eu sou um fotógrafo do tempo presente, que procuro trazer, dentro do universo das matrizes africanas, o olhar de quem está no mesmo barco da história, no mesmo caldeirão. Um olhar militante, de quem sempre lutou pelo fim do racismo e do preconceito de cor. Antes de tudo, sou um fotógrafo que penso, investigo e participo desse processo. Na história das artes no Ocidente, a representação da figura do negro sempre foi carregada de conotações negativas. Foi mostrado como uma espécie exótica e sem referenciais. Em minhas imagens procuro apontar para referências que são históricas e culturais, que sempre estiveram presentes dentro, é só uma questão do olhar.

Resgate - André Vilaron, qual o papel da fotografia, então? Vilaron - A fotografia tem um papel fundamental na construção (ou desconstrução) da imagem e na preservação de uma cultura. Interpretar aquilo que fotografamos - e aqui falo explicitamente do meu trabalho que tem como foco aspectos da tradição da cultura negro-africana no Brasil - é escolher o que será valorizado, aquilo que estará no seu foco e o que será deixado "fora do quadro", já que a fotografia é essencialmente um processo de escolha. Escolha do tema, dos personagens, do ângulo de visão, do momento e da forma como você irá se colocar diante das pessoas. E como aquilo que você aprende e vivencia, aquelas histórias e situações, serão recontadas dentro do seu trabalho artístico. Do ponto de vista da preservação da cultura, a prática dos rituais é a reafirmação da cultura de uma comunidade, uma forma que as pessoas têm de, pela prática e pela transmissão de conhecimento, não esquecerem quem são, de valorizarem sua cultura e sua tradição. Neste nãoesquecimento, a fotografia tem um papel importante como pre- servação, como memória. As primeiras imagens de meu trabalho são do início dos anos 1990. Acho que os dois aspectos importantes ligados à memória são a raridade de algumas delas e o efeito do tempo sobre parte das fotografias. Em relação a alguns momentos raros, gosto muito daquelas que trazem os malandros, a dança dos orixás, como Oxossi, no Catimbó, a presença de Legba em um terreiro, no Rio de Janeiro, a força do ritual do Candombe, nos Arturos, ou um tambor para Shango, no interior de Cuba. Com o tempo, algumas imagens parecem ganhar novas nuances. A fotografia, neste aspecto, tem a força de resgatar, de reiterar. Segundo Barthes, a fotografia não rememora $o$ passado. O efeito que ela produz não é o de restituir o que é abolido - pelo tempo, pela distância - mas o de atestar que "o que vejo de fato existiu".

\section{REFERÊNCIAS BIBLIOGRÁFICAS}

Atlântico Negro. Na Rota dos Orixás. Direção: Renato Barbieri. Filme-documentário. [S.I]. Produtora: Videografia, 1988, $54 \mathrm{~min}$, color, $35 \mathrm{~mm}$.

TURAZZI, Maria Inez. "Uma cultura fotográfica”. In: Revista do Patrimônio Histórico e Artístico Nacional n⿳⺈ 27, 1998, p.09. 